\title{
Variable Speed Pump Performance Characteristics for Domestic Application
}

\author{
Aisyah Jilani ${ }^{1}$ and Akhtar Razali* \\ Faculty of Mechanical Engineering, Universiti Malaysia Pahang, 26600 Pekan, Pahang, Malaysia
}

\begin{abstract}
Generally, water pumps work at a fixed speed. Structural resonance in fixed speed can cause vibration. The reason that most single speed pumps utilize an excessive amount of electricity is that they are overused and oversized. Therefore, this research is embarked to study the characteristic of a pressure-controlled variable speed pump, develop the variable speed pressure controlled pump and analyse the pump performance. A technique is proposed to change the constant speed pump to variable speed pump by adding Variable Frequency Drive (VFD) and microcontroller. A simple test rig is designed and fabricated represented of water distribution for domestic use. The method was then experimentally validated to verify the pump performance and energy used. Data for water flow rate, water pressure, power output and pump speed were analysed. Since the speed can be lowered until $29.27 \%$ which according to the water volume demands, therefore the power consumption was found decreased and the lowest power is $0.014 \mathrm{~kW}$. Maximum water discharge capability is $32.38 \mathrm{lpm}$. It is found that, a variable speed water pump able to save energy up to $97 \%$ and led to electricity bill saving and increase the life span of pipes and joints through less hydraulic pressure built-up.
\end{abstract}

\section{Introduction}

Fluid handling systems, for example fan and pump systems are culpable for a significant factor of total electrical energy use [1]. One of the larger cost elements is pumping energy and may overshadow a pump's life cycle costs, especially when the pumps work for more than $2000 \mathrm{~h}$ per year. There is a big potential for electricity consumption reduction can be made which through a proper selection and design of pumping systems and controls [2]. Motor speed can be changed by numerous methods for examples eddy current coupling or hydraulic, variable pulley and gear box system but most efficient method is by change the supply voltage and frequency to the motor [3]. In centrifugal load applications, energy consumption changed according to affinity laws which the torque is proportional to the square of speed, and power is proportional to the cube of speed. This variation helps to cut down the high energy losses compared to fixed-speed controllers or throttling devices for a relatively little reduction in speed [4].

\footnotetext{
*Corresponding author: akhtar@ump.edu.my
} 
By installing variable speed system, the speed of the motor is match with the related load where system loss reduction can be achieved. Due to variable speed system advantages, it has been boosting the popularity compared to traditional control methods [5]. Variable speed pump system can be achieved by adding Variable Frequency Drive (VFD) which can be used for controlling the speed of Electrical Generator or Electrical Machines [6]. Variable frequency drive (VFD) is a system made up of active/passive components of power electronics devices, sensing devices and high speed central controlling unit. It is a system that equipped for controlling the rotational speed of an alternating current (AC) electric motor by controlling the electrical power supplied frequency to the motor [7]. Generally, VFD have four fundamental sections which are input rectifier or converter, DC bus, output stack or VFD and the controller. The input rectifier converts the Vac input to Vdc and charges the capacitors in the part of the circuit. Next, DC bus function as a small reservoir for power on which the output of VFD draws. If any regenerated energy from the load remains, it is stored on the DC bus in the capacitors. From the DC bus, the output stack was used to draws power and creates a synthesized Vac power supply where the frequency of which can be varied by the controller. For the variable speed system, a variable speed drive was added between the motor and the power measurement equipment as shown in Fig. 1 [8]. R.Patel designed a VFD for industrial pump used that reduced $25 \%$ of power consumption with $10 \%$ reduction of operating speed and saves the energy cost [9].

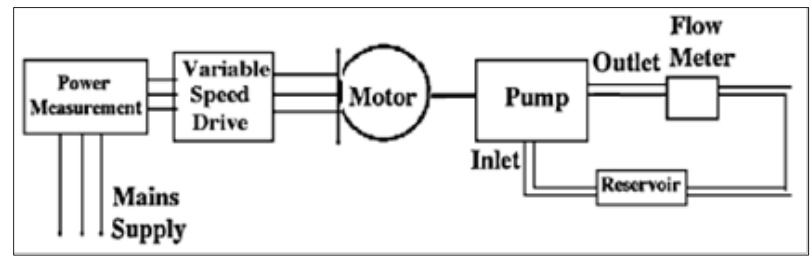

Fig. 1. Pump schematic diagram with variable speed drive control.

\section{Equipments and method}

The experiment consists of a centrifugal pump, pipes and joints, 6 valves, flow rate sensor, pressure sensor, pressure gauge, Variable Frequency Drive (VFD), Arduino microcontroller and power analyser. The test rig was built as illustrated of a terrace house pipeline as shown in Fig. 2. The experiment was set up as shown in schematic diagram in Fig. 3. The static head for both experiments was neglected. There were two factors that have been analysed which were the number of open valves and the type of valve opening.

In this experiment, microcontroller coding was created. Six valves were tested for an hour and the opening of the valve was $100 \%$ open and $50 \%$ open. There were 6 numbers of valves that has been tested one by one for an hour to see the flow trend. When the valves were open, the water flowed from the tank to the pump. The pump boosted the water and flowed through the pipe to the open valves. The water flow rate and water pressure inside the pipe were taken by flow rate and pressure sensor and the data sent to the microcontroller and VFD. The pressure sensor generates a signal as a function of the pressure imposed when the water through the pipe. A flow rate sensor was used to measure the flow rate or quantity of water that moving through a pipe. The function of Variable Frequency Drive is to control the frequency to match the water pressure inside the pipe. The microcontroller was used to run the Variable Frequency Drive automatically so that it can vary the frequency according to pressure in a pipe which is 3 psi. The rotation speed of the centrifugal pump disk was measured by a tachometer. Furthermore, energy meter analyser was used to measure the amount of electrical energy used by the centrifugal pump. Polypipe material was used to let 
the water flow from tank to valve. All data were analysed to see the pump performance of variable speed pump. According to Affinity laws (equation 1,2,3) which are mathematical relationships, by changing the pump speed, there are estimation of the changes in the pump performance curves $[10] \mathrm{Q}=$ Flowrate, $\mathrm{P}=$ pressure, $\mathrm{W}=$ power, $\mathrm{N}=$ speed.

$$
\begin{aligned}
& \frac{Q_{2}}{Q_{1}}=\frac{N_{2}}{N_{1}} \\
& \frac{P}{P_{1}}=\left(\frac{N_{2}}{N_{1}}\right)^{2} \\
& \frac{W_{2}}{W_{1}}=\left(\frac{N_{2}}{N_{1}}\right)^{3}
\end{aligned}
$$

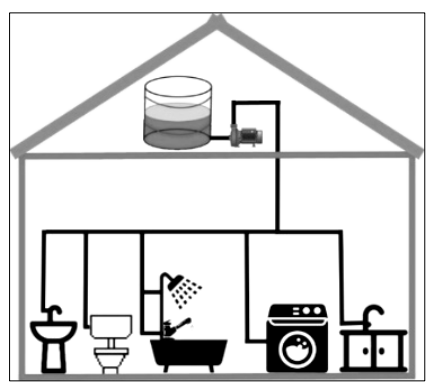

Fig. 2. Piping of water distribution in a terrace house.

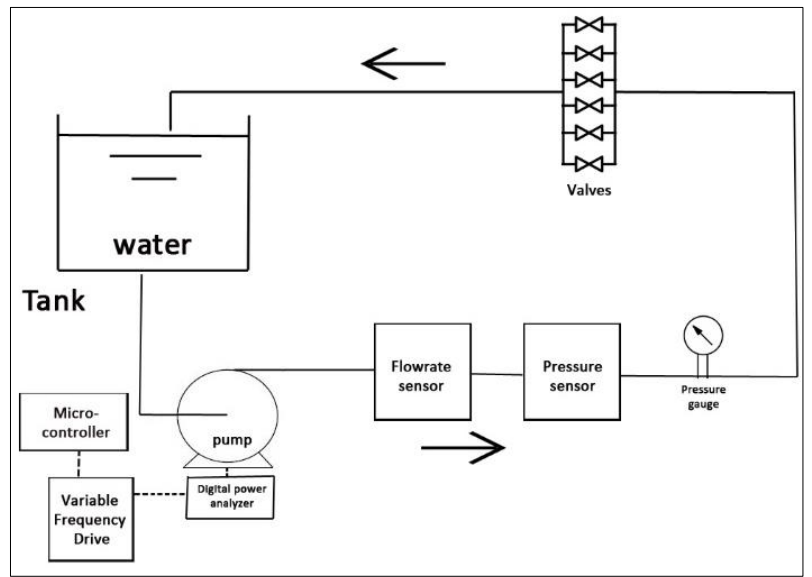

Fig. 3. Schematic diagram of experiment flow.

\section{Results and discussion}

The results from experimental work were displayed as shown in Table 1 for $50 \%$ open valve and Table 2 for $100 \%$ open valve. The water pressure in the pipe was maintained for $3 p s i$. Most of conventional pumps used for domestic application were fixed speed and run at maximum speed which is $100 \%$. In the table, it can be seen that, the pattern of increment and decrement of parameter for both $50 \%$ and $100 \%$ type of opening were almost the same. Furthermore, less number of open valve reduced the speed of the pump. The pump's power 
was drop when the rotational speed of impeller slowed down which made the VFD saved significant amounts of power by matching pump speed to load requirements. This method is more efficient than running a pump at full speed and throttling its output and also cuts the maintenance costs [11]. For example, 1 full open valve only need $37.75 \%$ of pump's speed for delivered the water.

Table 1. Results for variable speed pump 50\% open valve

\begin{tabular}{|c|c|c|c|c|c|c|c|}
\hline $\begin{array}{c}\text { Open } \\
\text { valve }\end{array}$ & $\begin{array}{c}\text { Speed } \\
(\mathbf{\%})\end{array}$ & $\begin{array}{c}\text { Pressure } \\
(\mathbf{p s i})\end{array}$ & $\begin{array}{c}\text { Power } \\
(\mathbf{k W})\end{array}$ & $\begin{array}{c}\text { Flow rate } \\
(\mathbf{l p m})\end{array}$ & $\begin{array}{c}\text { Head } \\
(\mathbf{m})\end{array}$ & $\begin{array}{c}\text { Volume } \\
(\boldsymbol{\ell})\end{array}$ & $\begin{array}{c}\text { Energy } \\
\text { saving (\%) }\end{array}$ \\
\hline 1 valve & 29.27 & 3.04 & 0.014 & 4.65 & 2.14 & 279.00 & 97.31 \\
\hline 2 valves & 36.40 & 3.06 & 0.026 & 7.80 & 2.15 & 468.00 & 95.00 \\
\hline 3 valves & 41.44 & 3.07 & 0.037 & 10.19 & 2.16 & 611.40 & 92.88 \\
\hline 4 valves & 51.60 & 3.03 & 0.075 & 14.09 & 2.13 & 845.40 & 85.58 \\
\hline 5 valves & 60.03 & 3.00 & 0.120 & 17.07 & 2.11 & 1024.20 & 76.92 \\
\hline 6 valves & 72.92 & 3.00 & 0.215 & 20.49 & 2.11 & 1229.40 & 58.65 \\
\hline
\end{tabular}

Table 2. Results for variable speed pump 100\% open valve

\begin{tabular}{|c|c|c|c|c|c|c|c|}
\hline $\begin{array}{c}\text { Open } \\
\text { valve }\end{array}$ & $\begin{array}{c}\text { Speed } \\
(\mathbf{\%})\end{array}$ & $\begin{array}{c}\text { Pressure } \\
(\mathbf{p s i})\end{array}$ & $\begin{array}{c}\text { Power } \\
(\mathbf{k W})\end{array}$ & $\begin{array}{c}\text { Flow rate } \\
(\mathbf{l p m})\end{array}$ & $\begin{array}{c}\text { Head } \\
(\mathbf{m})\end{array}$ & $\begin{array}{c}\text { Volume } \\
(\boldsymbol{\ell})\end{array}$ & $\begin{array}{c}\text { Energy } \\
\text { saving (\%) }\end{array}$ \\
\hline 1 valve & 37.75 & 3.04 & 0.030 & 9.05 & 2.14 & 543.00 & 94.23 \\
\hline 2 valves & 51.27 & 3.05 & 0.075 & 14.13 & 2.14 & 847.80 & 85.58 \\
\hline 3 valves & 64.48 & 3.05 & 0.146 & 18.73 & 2.14 & 1123.80 & 71.92 \\
\hline 4 valves & 80.05 & 3.00 & 0.260 & 23.16 & 2.11 & 1389.60 & 50.00 \\
\hline 5 valves & 93.39 & 3.00 & 0.400 & 28.62 & 2.11 & 1717.20 & 23.08 \\
\hline 6 valves & 98.16 & 3.00 & 0.490 & 32.38 & 2.11 & 1942.80 & 5.77 \\
\hline
\end{tabular}

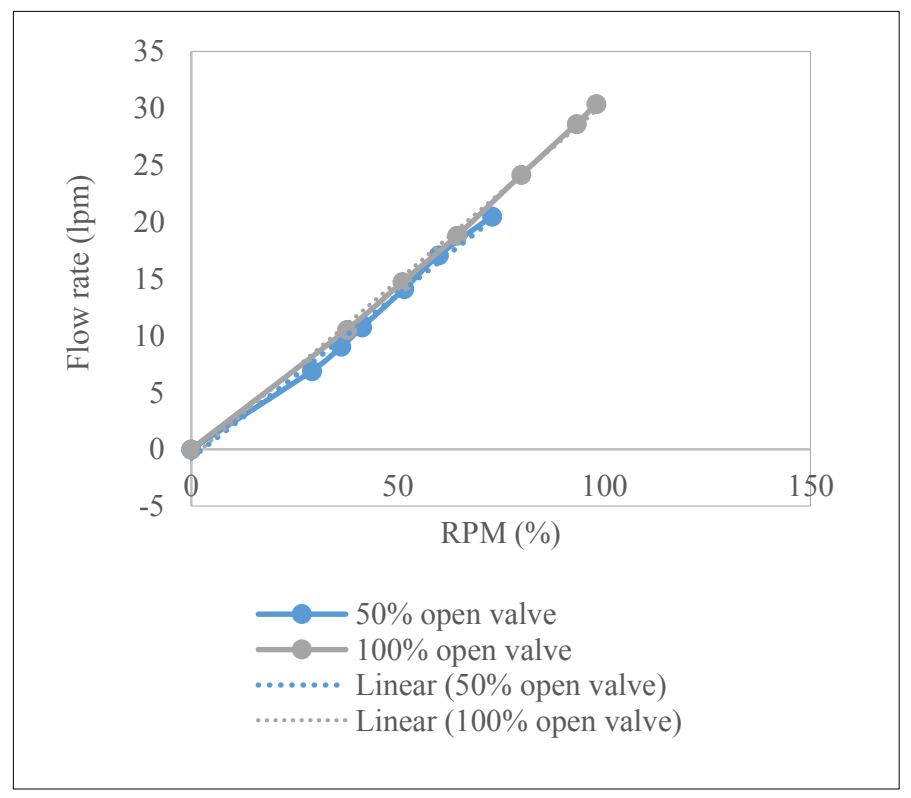

Fig. 4. Relationship between speed of pump and water flowrate. 


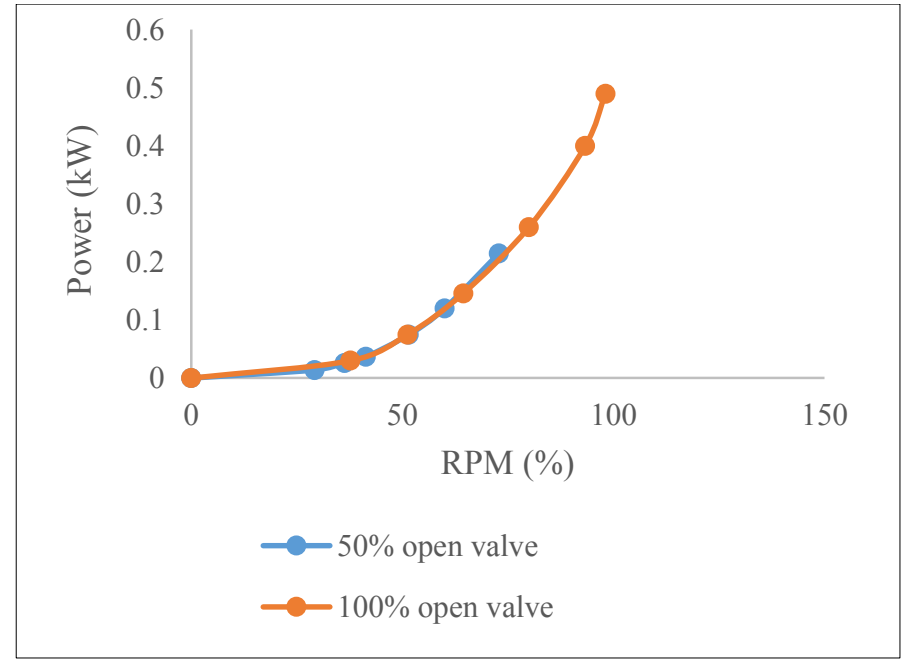

Fig. 5. Relationship between speed of pump and power.

The graph as seen in Fig. 4 illustrates the water flow rate in pipe and pump's speed relationship. As the speed increased, the water flow rate also increased linearly. The volume of water also increased when the velocity of water increased because the number of valve opened was high due to larger area at the outlet of the valve. Fig. 5 showed the relationship between pump speed and power which is increased in cubic function graphically. The affinity laws state that when the speed of pump change, there were changes in pump flow rate, pressure and power which is a linear, squared and cubic function respectively [12]. A small change in motor speed can cause a significant change in energy consumption. Energy saving were calculated as shown in the Table 1 and 2 . The less the number of valve open, the higher the energy saving. It is experimentally proved that by adding VFD to conventional motor that can varied the motor speed for domestic application would result in saving up to $91 \%$ of the energy used. Energy consumption indeed falls far more than decreasing in motor speed, so the savings can grow rapidly [13]. For instance, a 20\% reduction in motor pump speed results in a $50 \%$ decreased in power consumption.

\section{Conclusion}

The experimental observation showed that the pump speed can be controlled automatically by adding VFD and microcontroller for domestic application. The pressure was fixed and followed the piping standard at 3 psi. The highest number of open valve produced the highest power which are $0.490 \mathrm{~kW}$. The maximum water discharge capability was $32.38 \mathrm{lpm}$. Pump performance and characteristic of variable speed pump also was proved by the affinity law. The reason variable speed motors work efficiently for centrifugal pumps can be understood from the Pump Affinity Laws which stated that flow rate is proportional to pump speed, pressure is proportional to pump speed squared and power of the pump is proportional to pump speed cubed. The benefit of using a variable speed pump for water distribution system as energy saving also applicable for domestic application instead of industrial purpose. In terms of energy, the variable speed pump able to saved up to $97 \%$. Furthermore, this paper could be useful for plumbers or contractor to completely understand energy saving 
opportunities in electric motors and further to take proper actions for energy saving measures to enhance energy efficiency in residential area. This could help researcher adopt proper design concepts and options in the decision-making process during the primary planning and design stages to apply this concept probably for higher horsepower pump and better system to decrease the global energy consumption in electric motors, environmental sustainability and improve control stability. It also could be affordable and useful for the government to assess the current electric motor energy policies.

\section{References}

1. J. Tamminen, J. Viholainen, T. Ahonen, J. Ahola, S. Hammo, V., E., Energy Efficiency, 7, 493-505 (2014)

2. I. Sarbu, E. Valea, Sustainability, 7, 5705-5719 (2015)

3. P. Dave, K. Mokariya, V. Patel, International Journal of Innovative Research in Science, Engineering and Technology (IJIRSET), 02, 1461-1468 (2013)

4. E.A. Abdelaziz, R. Saidur, S. Mekhilef, Renewable and Sustainable Energy Reviews, 15, 150-168 (2011)

5. R. Saidur, N.A. Rahim, H.W. Ping, M.I. Jahirul, S. Mekhilef, H.H. Masjuki, Energy Policy, 37, 3650-3658 (2009)

6. A. Kale, N.R. Kamdi, P. Kale, A.A. Yeotikar, International Research Journal of Engineering and Technology (IRJET), 04, 1281-1284 (2017)

7. A. Dharkar, International Journal of Electrical Engineering \& Technology (IJEET), 8, 45-51 (2017)

8. M. Patel, P.K. Sen, G. Sahu, International Journal of Innovative Research in Technlogy (IJIRT), 2, 12-15 (2015)

9. R. Patel, N. Sheth, K. Patel, International Journal of Application or Innovation in Engineering \& Management (IJAIEM), 04, 181-188, (2015)

10. A. Moubarak, G. El-saady, E. Ibrahim, Journal of Power and Energy Engineering, 5, 5071 (2017)

11. J. Rekola, Advantages of Variable Speed Drive in Pump Applications. (Sähkötekniikan koulutusohjelma master thesis), Tampere University of Technology. Retrieved from http://URN.fi/URN:NBN:fi:tty-201510191644 (2014)

12. A. Marchi, A.R. Simpson, Journal of Water Resources Planning and Management, 139, 1314-1317 (2013)

13. R. Saidur. Journal of Renewable and Sustainable Energy Reviews, 14, 877-898 (2009) 